\title{
Hydrothermal stability of some manganese oxides
}

\author{
J A K TAREEN, B BASAVALINGU $\dagger$, G T BHANDAGE* and \\ T R N KUTTY** \\ Mineralogical Institute, University of Mysore, Mysore 570 006, India \\ *Department of Chemistry, Regional College of Education, Mysore 570 006, India \\ **Materials Research Laboratory, Indian Institute of Science, Bangalore 560012 , India \\ MS received 21 November 1987; revised 2 January 1988
}

\begin{abstract}
Hydrothermal phase reaction studies in the systems $\beta-\mathrm{MnO}_{2}-\mathrm{H}_{2} \mathrm{O}, \gamma-\mathrm{Mn}_{2} \mathrm{O}_{3}$ $\mathrm{H}_{2} \mathrm{O}$ and $\gamma-\mathrm{MnO}_{2}-\mathrm{H}_{2} \mathrm{O}$ have been carried out. Based on the experimental data and the reported phase diagrams in $\mathrm{Mn}_{2} \mathrm{O}_{3}-\mathrm{H}_{2} \mathrm{O}$ and $\mathrm{MnO}-\mathrm{H}_{2} \mathrm{O}$ systems, hydrothermal stability temperature of some of the manganese oxide minerals has been defined.
\end{abstract}

Keywords. Hydrothermal stability; manganese oxide.

\section{Introduction}

Several forms of manganese-oxygen compounds are known to occur as natural minerals or as synthesized manganese oxides. The phase relations of manganese oxides under differing conditions of temperature and pressure are particularly interesting since many of the manganese oxide deposits are metamorphosed manganese-containing sediments. Earlier studies were mainly confined to the stability conditions of manganese oxides, either as a function of $\mathrm{Eh}$ and $\mathrm{PH}$, as in the systems $\mathrm{Mn}-\mathrm{H}_{2} \mathrm{O}, \mathrm{Mn}-\mathrm{CO}_{2}-\mathrm{H}_{2} \mathrm{O}, \mathrm{Mn}-\mathrm{S}-\mathrm{CO}_{2}-\mathrm{H}_{2} \mathrm{O}$ at $25^{\circ} \mathrm{C}$ and one atmosphere pressure (Hem 1972) or at elevated temperatures and one atmosphere in air or oxygen (Faulring et al 1960; Hahn and Muan 1960; Lima-da-Faria and Lopes Vieira 1964; Ukai et al 1959). A review of the literature shows reports of equilibria diagrams of the systems $\mathrm{MnO}-\mathrm{H}_{2} \mathrm{O}, \mathrm{Mn}_{2} \mathrm{O}_{3}-\mathrm{H}_{2} \mathrm{O}$ (Klingsberg and Roy 1959) and $\mathrm{KMnO}_{4}$ $\mathrm{H}_{2} \mathrm{O}$ (Endo et al 1974). The present study pertains to the hydrothermal phase equilibria of $\beta-\mathrm{MnO}_{2}-\mathrm{H}_{2} \mathrm{O}, \gamma-\mathrm{MnO}_{2}-\mathrm{H}_{2} \mathrm{O}$ and $\gamma-\mathrm{Mn}_{2} \mathrm{O}_{3}-\mathrm{H}_{2} \mathrm{O}$ systems and from the available data the sequence of stability of manganese minerals has been correlated for different starting compounds. Since the stellite vessels used for all the runs were sufficiently old and the pressurising fluid water reacts with the walls of the vessel to generate hydrogen which permeate through the platinum tubes. This corresponds to an oxygen fugacity comparable to $\mathrm{Ni}-\mathrm{NiO}$ buffer (Eugster and Wones 1962).

\section{Experimental method}

The starting compounds used in the present study were $\beta-\mathrm{MnO}_{2}, \gamma-\mathrm{MnO}_{2}$ and $\gamma-$ $\mathrm{Mn}_{2} \mathrm{O}_{3} \cdot \beta-\mathrm{MnO}_{2}$ (pyrolusite) used was the commercially available AR grade powder. $\gamma-\mathrm{MnO}_{2}$ compound was from Union Carbide India Ltd. (battery grade material) prepared by electrolytic process. $\gamma-\mathrm{Mn}_{2} \mathrm{O}_{3}$ was prepared by hydrolyzing

†To whom all correspondences should be addressed. 
manganese chloride with IM NaOH solution and the precipitate was aged on hot water bath for a few hours before it was filtered and dried in hot air-oven at $150^{\circ} \mathrm{C}$. All the hydrothermal runs were carried out with tuttle type stellite reactors by charging the starting compounds in platinum ampoules $(5 \mathrm{~cm} \times 0.5 \mathrm{~mm}$ dia with $0.1 \mathrm{~mm}$ wall thickness). The starting compounds were the respective oxides $(100$ $200 \mathrm{mg}$ ) and double distilled water $\left(6-7\right.$ drops), thus $P_{\text {total }}=P_{\mathrm{H}_{2} \mathrm{O}}$. The ampoules were sealed by arc welding and checked for any leakage by extended heating at $100^{\circ} \mathrm{C}$ in hot air oven and noting the weight differences if any. The ampoules showing any weight loss were discarded. The vessel with the charge was first pressurised with water medium and then introduced into the preheated furnace. After attaining the desired pressure and temperature, it was allowed for $60-80 \mathrm{~h}$ of uninterrupted run. At the end of the run the reaction was arrested by quenching the vessels with compressed air blast, until the ambient temperature was achieved. The remaining pressure was then vented out. The products were identified by the X-ray powder method. The accuracy of temperature and pressure controls was within $\pm 5^{\circ} \mathrm{C}$ and \pm 10 bars respectively.

\section{Results}

The phase diagram for $\beta-\mathrm{MnO}_{2}-\mathrm{H}_{2} \mathrm{O}$ is given in figure 1. The sequence of decomposition of $\beta$ - $\mathrm{MnO}_{2}$ with increasing temperature is as follows

$$
\begin{aligned}
2 \beta-\mathrm{MnO}_{2} & \longrightarrow \mathrm{Mn}_{2} \mathrm{O}_{3}+0.5 \mathrm{O}_{2}, \\
3 \mathrm{Mn}_{2} \mathrm{O}_{3} & \longrightarrow 2 \mathrm{Mn}_{3} \mathrm{O}_{4}+0.5 \mathrm{O}_{2}, \\
\mathrm{Mn}_{3} \mathrm{O}_{4} & \longrightarrow 3 \mathrm{MnO}+0.5 \mathrm{O}_{2} .
\end{aligned}
$$

The phase boundaries between different oxide fields have steep positive slopes, which decrease as we go towards the field of lower oxides indicating that these are more and more pressure-dependent. The boundary with almost $45^{\circ}$ positive slope

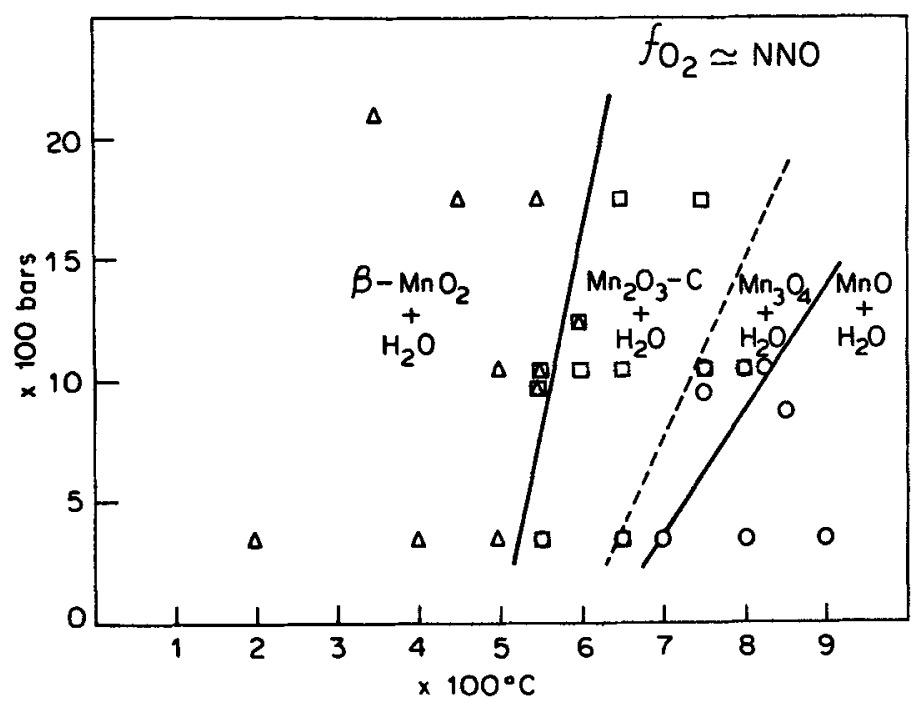

Figure 1. Phase diagram for $\beta-\mathrm{MnO}_{2}-\mathrm{H}_{2} \mathrm{O}$ system. 
suggests an almost equal dependence of temperature and pressure. This behaviour of change of slope was also observed by Endo et al (1974).

In the case of $\gamma-\mathrm{MnO}_{2}-\mathrm{H}_{2} \mathrm{O}$ system, few isobaric ( $1 \mathrm{kbar}$ ) runs were carried out to understand the sequence of reactions. The $\gamma-\mathrm{MnO}_{2}$ changes to $\beta-\mathrm{MnO}_{2}$ at $220^{\circ} \mathrm{C}$ and then appears as lower oxides in the same sequence as in $\beta-\mathrm{MnO}_{2}-\mathrm{H}_{2} \mathrm{O}$ system.

The sequence of decomposition of $\gamma-\mathrm{Mn}_{2} \mathrm{O}_{3}$ in $\gamma-\mathrm{Mn}_{2} \mathrm{O}_{3}-\mathrm{H}_{2} \mathrm{O}$ system is:

$$
\gamma-\mathrm{Mn}_{2} \mathrm{O}_{3} \longrightarrow 2 \mathrm{MnO}+0.5 \mathrm{O}_{2} \text {. }
$$

The phase diagram of the above system is given in figure 2 . It may be noted that $y$ $\mathrm{Mn}_{2} \mathrm{O}_{3}$ was expected to decompose to $\mathrm{MnO}$ via the intermediate field of $\mathrm{Mn}_{3} \mathrm{O}_{4}$. But due to difficulty in distinguishing between $\gamma-\mathrm{Mn}_{2} \mathrm{O}_{3}$ and $\mathrm{Mn}_{3} \mathrm{O}_{4}$ by X-ray powder data the $\mathrm{Mn}_{3} \mathrm{O}_{4}$ field could not be established. In fact, more often $\gamma-\mathrm{Mn}_{2} \mathrm{O}_{3}$ is quoted in the literature as pseudo-hausmannite (ASTM Card no. 18.803).

$\mathrm{X}$-ray powder diffraction data of the stable phases in all the above systems are given in table 1.

\section{Discussion}

The hydrothermal study of the manganese oxide systems has brought out certain interesting features concerning the stability of the different manganese oxides. The stabilization of hydrous phases was not found in the hydrothermal systems $\beta-\mathrm{MnO}_{2}$ $\mathrm{H}_{2} \mathrm{O}, \gamma-\mathrm{MnO}_{2}-\mathrm{H}_{2} \mathrm{O}$ and $\gamma-\mathrm{Mn}_{2} \mathrm{O}_{3}-\mathrm{H}_{2} \mathrm{O}$, although some of the runs were carried out at very low temperatures $\left(\simeq 150^{\circ} \mathrm{C}\right)$ and for durations as long as $200 \mathrm{~h}$. Similarly, only the anhydrous phases like $\mathrm{K}_{2} \mathrm{Mn}_{7} \mathrm{O}_{14}$ and $\mathrm{KMn}_{8} \mathrm{O}_{16}$ were reported in the low temperature regions of $\mathrm{KMnO}_{4}-\mathrm{H}_{2} \mathrm{O}$ system (Endo et al 1974). In the $\mathrm{MnO}-\mathrm{H}_{2} \mathrm{O}$ and $\mathrm{Mn}_{2} \mathrm{O}_{3}-\mathrm{H}_{2} \mathrm{O}$ systems, Klingsberg and Roy (1959) reported $\mathrm{Mn}(\mathrm{OH})_{2}$ and $\mathrm{MnOOH}$ hydrous phases at low temperatures but their attempt to stabilize hydrohausmannite from $\mathrm{Mn}_{3} \mathrm{O}_{4}$ was unsuccessful.

The lower limit of the hydrothermal stability range of the manganese oxide mineral depends on the parent material from which the oxide is derived, while the

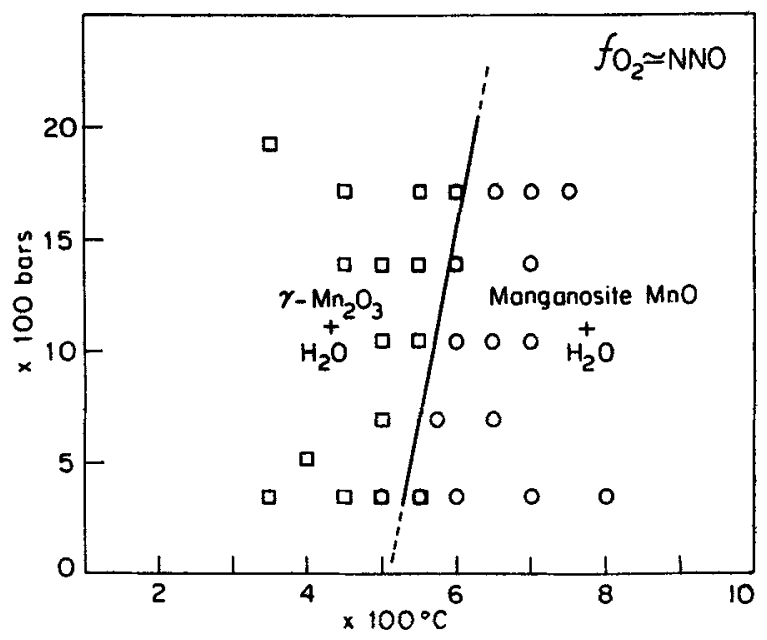

Figure 2. Phase diagram for $\gamma-\mathrm{Mn}_{2} \mathrm{O}_{3}-\mathrm{H}_{2} \mathrm{O}$ system. 
Table 1. X-ray diffraction data.

\begin{tabular}{|c|c|c|c|c|c|c|c|c|c|c|c|}
\hline & & $\beta-\mathbf{M}$ & & $\mathrm{Mr}$ & & $\gamma-\mathbf{M}$ & & $\mathbf{M n}$ & & & \\
\hline $\mathrm{d} \AA$ & I & $\mathrm{d} \AA$ & I & $\mathrm{d} \AA$ & I & $\mathrm{d} \AA$ & I & $\mathrm{d} \AA$ & I & $\mathrm{d} \AA$ & I \\
\hline 4.01 & $\mathrm{mw}$ & 3.480 & $\mathbf{w}$ & 3.849 & $\mathrm{~ms}$ & $4 \cdot 913$ & $\mathrm{~m}$ & 4.935 & $\mathbf{w}$ & $2 \cdot 560$ & $\mathbf{s}$ \\
\hline $2 \cdot 41$ & $\mathrm{~ms}$ & $3 \cdot 120$ & vs & $2 \cdot 717$ & vs & 3.087 & $\mathbf{s}$ & 3.085 & $\mathrm{~m}$ & $2 \cdot 214$ & vs \\
\hline $2 \cdot 11$ & vs & $2 \cdot 410$ & $\mathbf{s}$ & 2.359 & mw & $2 \cdot 881$ & vw & 2.883 & $w$ & 1.567 & $\mathbf{s}$ \\
\hline 1.62 & $\mathrm{~ms}$ & $2 \cdot 206$ & vw & $2: 214$ & vvw & $2 \cdot 770$ & $\mathbf{s}$ & $2 \cdot 762$ & $\mathbf{s}$ & 1.339 & $\mathrm{mw}$ \\
\hline & & $2 \cdot 115$ & $\mathbf{m}$ & $2 \cdot 114$ & $\mathbf{v w}$ & $2 \cdot 490$ & vs & 2.560 & vvw & & \\
\hline & & 1.972 & $\mathbf{w}$ & 1.840 & $\mathbf{m}$ & $2 \cdot 368$ & mw & 2.491 & vs & & \\
\hline & & 1.830 & vw & 1.661 & $\mathbf{s}$ & $2 \cdot 040$ & $\mathbf{m}$ & $2 \cdot 341$ & mw & & \\
\hline & & 1.626 & ms & 1.530 & $\mathbf{v w}$ & 1.830 & vw & 2.034 & $\mathrm{mw}$ & & \\
\hline & & 1.558 & $\mathbf{m}$ & 1.418 & $\mathrm{~m}$ & 1.796 & mw & 1.819 & vw & & \\
\hline & & 1.431 & $\mathbf{w}$ & 1.414 & vvw & 1.699 & vw & 1.785 & $\mathbf{m}$ & & \\
\hline & & 1.398 & vvw & & & 1.640 & vw & 1.701 & $w$ & & \\
\hline & & & & & & 1.575 & $\mathrm{mw}$ & 1.639 & $\mathbf{s}$ & & \\
\hline & & & & & & 1.544 & $\mathrm{~ms}$ & 1.570 & $\mathrm{~m}$ & & \\
\hline & & & & & & 1.436 & $\mathrm{vw}$ & 1.540 & $\mathrm{~ms}$ & & \\
\hline & & & & & & 1.380 & vw & 1.462 & vw & & \\
\hline & & & & & & $1 \cdot 343$ & $\mathbf{w}$ & 1.442 & $\mathrm{mw}$ & & \\
\hline
\end{tabular}

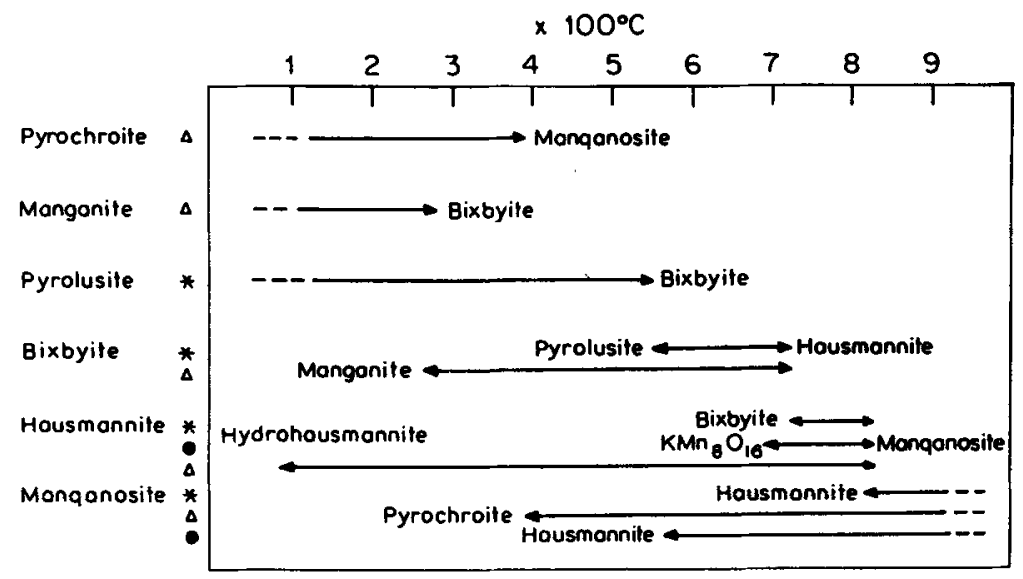

Figure 3. Stability temperatures of some manganese oxide minerals at $1 \mathrm{kbar}$ water vapour pressure based on the hydrothermal phase reaction studies ( $\Delta$ Klingsberg and Roy 1959; Endo et al 1974; *present work).

maximum stability temperature is the same irrespective of the parent material (figure 3). For instance, bixbyite stability ranges from 550 to $725^{\circ} \mathrm{C}$ when the parent material is pyrolusite, but when derived from manganite the formation of bixbyite is at $275^{\circ} \mathrm{C}$. The stability of manganese oxide minerals also depends on several factors such as soluble ions like $\mathrm{K}, \mathrm{Ba}, \mathrm{Na}$, etc. in the hydrothermal fluid. Work in this direction is currently in progress in this laboratory.

\section{References}

Endo T, Kume S, Shimada M and Koizumi M 1974 Mineral. Mag. 39559

Eugster H P and Wones D R 1962 J. Petrol. 382 
Faulring G M, Zwicker W K and Forgong W D 1960 Am. Mineral. 45946

Hahn W C and Muan A 1960 Am. J. Sci. 25866

Hem J D 1972 Geol. Soc. Am. Bull. 83443

Klingsberg C and Roy R 1959 Am. Mineral. 44819

Lima-da-Faria J and Lopes Vieira A 1964 Mineral. Mag. 331024

Ukai Y, Nishimuta S and Mayeda T 1956 Mem. Coll. Sci. Univ. Kyoto Ser. B23 203 